\title{
Erratum to: One-year incidence and prevalence of seclusion: Dutch findings in an international perspective
}

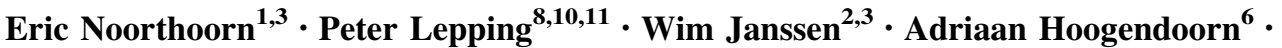 \\ Henk Nijman ${ }^{4,5}$ - Guy Widdershoven ${ }^{7}$. Tilman Steinert ${ }^{9}$
}

Published online: 25 September 2015

(c) Springer-Verlag Berlin Heidelberg 2015

\section{Erratum to: Soc Psychiatry Psychiatr Epidemiol DOI 10.1007/s00127-015-1094-2}

In the Table 3 of the original publication, the value " 32 " in 5 th column has been misplaced. It should belong to the third row instead of the fourth row. The correct version of Table 3 is given below:

The online version of the original article can be found under doi:10.1007/s00127-015-1094-2.

\section{Eric Noorthoorn}

E.Noorthoorn@ggnet.nl

1 GGnet Community Mental Health Centre, Warnsveld, The Netherlands

2 Hogeschool Windesheim, Zwolle, The Netherlands

3 Dutch Case Register Coercive Measures, Altrecht Aventurijn, Den Dolder, The Netherlands

4 Radboud University of Nijmegen, Nijmegen, The Netherlands

5 Altrecht Aventurijn, Den Dolder, The Netherlands

6 Department of Psychiatry, EMGO+ Institute for Health and Care Research, VU University Medical Center, Amsterdam, The Netherlands
7 Department of Medical Humanities, EMGO Institute for Health and Care Research, VU University Medical Center, Amsterdam, The Netherlands

8 Bangor University (Centre for Mental Health and Society), Bangor, Wales, United Kingdom

9 Centres for Psychiatry Suedwuerttemberg, Ulm University, Ulm, Germany

10 Mysore Medical College and Research Institute, Mysore, India

11 Betsi Cadwaladr University Health Board, Wrexham, Wales 


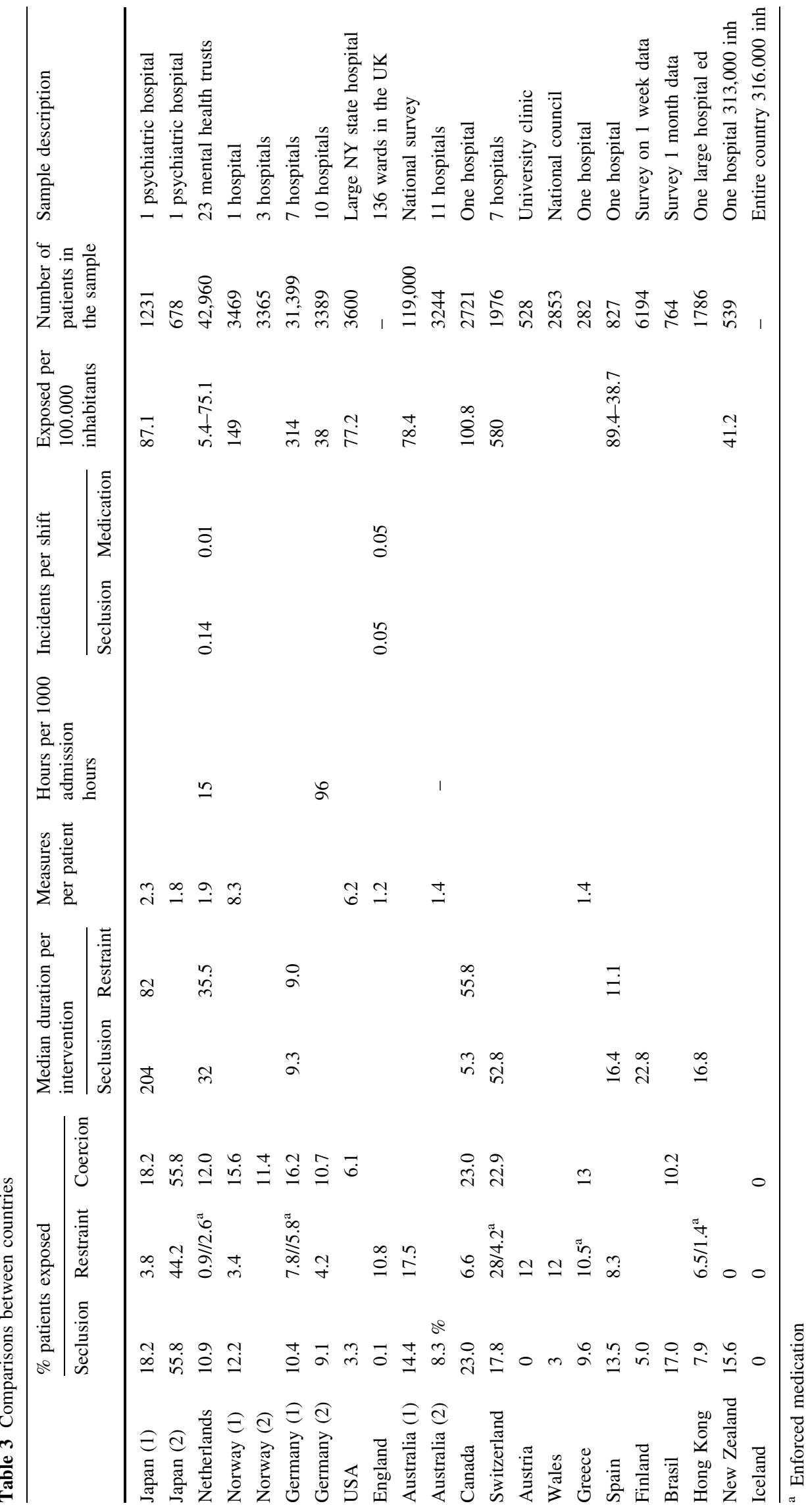

